\title{
THE DISTRIBUTION AND RETENTION OF YTTRIUM AND LANTHANUM IN CAST SINGLE CRYSTAL SUPERALLOYS
}

\author{
S.P. Leyland ${ }^{1}$, I.M Edmonds ${ }^{2}$, S. Irwin ${ }^{2}$, C.N. Jones ${ }^{2}$, A. Bhowmik ${ }^{3}$, D. Ford ${ }^{4}$, C.M.F. Rae ${ }^{1}$ \\ ${ }^{1}$ Materials Science and Metallurgy, Cambridge University, 27 Charles Babbage Rd, Cambridge CB3 0FS, UK. \\ ${ }^{2}$ Rolls-Royce plc. PO Box 31, Elton Road, Derby, DE24 8BJ, UK. \\ ${ }^{3}$ Imperial College, Exhibition Road, London, UK. \\ ${ }^{4}$ European Investment Casters' Federation, 220 Mendip Rd, Yatton, Bristol, Avon, BS49 4DG, UK.
}

Keywords: Casting, Superalloys, REM, Reactive Elements, yttrium, lanthanum, ®-4

\begin{abstract}
Reactive elements (REs) are added to superalloys to improve their resistance to oxidation. They act by "gettering" free sulphur in the alloy; sulphur which would otherwise migrate to the oxide alloy interface thus weakening the adhesion of the oxide [1]. However, RE dopants can be detrimental to mechanical properties, lowering the incipient melting point and increasing the propensity to precipitate TCP phases [2]. We report a systematic series of casting trials designed to quantify the losses of REs during casting and heat treatment of the alloy CMSX-4® ${ }^{1}$. [3]. These results show a consistent pattern, demonstrating that the principal factor of RE losses are the nature of the mold and core material and the surface area to volume ratio of the cast component. Several other process parameters are identified that can be carefully controlled to minimise loss. These include the vacuum level, casting temperature and solidification withdrawal time. The location, composition and structure of the RE-containing phases and outlined how they affect the likely supply of these elements, and hence the environmental performance, throughout the service life of the component.
\end{abstract}

\section{Introduction}

It has been known for over 30 years that the addition of reactive elements (REs) to superalloys has a beneficial effect on the environmental resistance of these alloys. Although there is no unifying theory established to fully explain how RE dopants improve oxidation resistance, one of their main roles is the gettering of sulphur in the matrix [4]. However, their use as a routine addition to superalloys has not become widespread because of difficulties in ensuring a predicable concentration of these elements throughout a complex component, sufficient to guarantee protection.

This paper describes the first comprehensive and systematic study of the key casting process parameters that affect RE losses during single crystal casting of CMSX-4. RE distribution, location, composition and structure of the RE-containing phases are identified in the as-received barstock and in their subsequent distribution after casting and heat-treatment. The optimum concentration of RE in the alloy is difficult to define [5]. Insufficient RE does not improve oxidation resistance whilst excess amounts have been shown to have a detrimental effect on mechanical properties [2]. Hence there exists a careful balance between adding sufficient RE dopant to be effective, and causing detriment to the alloy. Advances in casting technology have made

\footnotetext{
${ }^{1}$ CMSX-4® is a registered Trade mark of the Cannon-Muskegon Company
}

it possible to achieve ultra low levels of sulphur where the oxidation performance is comparable to RE-containing alloys without these damaging effects. Such "Super Low Sulphur" (SLS) alloys are considered to be a low risk alternative until controllable and repeatable RE dopant methods are established [6].

Designing a casting system requires understanding of the parameters that affect RE losses and minimize casting anomalies. Casting parameters need to be controlled in order to achieve RE retention targets, notably solidification time, vacuum level, and casting/solidification temperature. Chemical reactions between the $\mathrm{RE}$ dopant and the refractory depend on the choice of the shell mold and the core refractory materials and their relative inertness. Component design features also influence RE retention. Large differences in RE retention occur in different section thicknesses with over doping in thick sections, but under doping in thinner sections, especially in blade sections formed with silica cores. This work aims to show that, understanding the RE chemical reaction and physical loss mechanisms during the casting cycle, will help the casting engineer to optimize the key process input parameters, necessary to optimise the distribution of RE dopants, throughout the cast component.

\section{Casting Details;}

\section{Experimental}

A series of casting trials was devised to examine the different sources of $\mathrm{Y}$ loss by systematically varying the casting parameters. The selected casting parameters included, solidification time, temperature and vacuum levels; choice of casting refractory materials used for the melting crucible, and most critically, the mold and core materials, and the component geometry. All casting trials in this study were conducted in an 7" chill plate single crystal casting unit at the Rolls-Royce Plc. Company Research and Development Foundry, Bristol, UK. All casting trials were melted in an aluminosilicate ceramic fibre crucible within a separate vacuum chamber. Standard casting parameters refer to: a casting temperature of $1475{ }^{\circ} \mathrm{C}$, solidification withdrawal rate of $2.2 \mathrm{~mm} \mathrm{~min}^{-1}$ (equivalent to a total withdrawal time of 90 mins) at a vacuum level of $4 \times 10^{-4} \mathrm{~Pa}$. The Y dopant was added to the Ni-based alloy CMSX-4 in the form of intermetallic $\mathrm{Y}$ at the melting stage, or as pre-doped alloy barstock ranging from $50 \mathrm{ppm}$ to $5000 \mathrm{ppm}$.

The first trial that was conducted used standard casting parameters and process refractories. The mold contained a multi-component casting configuration consisting of a range of components that were either solid or their section thickness was thinned by a silica core, including a silica cored HP turbine blade. These test components represented a variety of wall thicknesses and 
geometric shapes common to gas turbine components. This zircon shell mold was designed to benchmark retention levels using existing casting conditions and refractory shell materials. A predoped alloy containing $1126 \mathrm{ppm} \mathrm{Y}$ was available that was considered sufficient to achieve RE retention in the solid and cored sections. The same multi-component mold configuration was used systematically to identify the retention levels of low and high RE dopant levels in four different inert shell refractories, silica/zircon, alumina, alumina/yttria and yttria. The effect of fast and slow solidification rates, and the effect of elevating the casting temperature to $1550{ }^{\circ} \mathrm{C}$ were also investigated. A second mold configuration consisting of $12 \mathrm{~mm}$ diameter test bars was used to investigate the effect of varying the vacuum level, and a wider range of $\mathrm{Y}$ doping levels.

\section{Analysis of RE retention}

The resulting cast bars and blades were sectioned to assess the levels of yttrium and lanthanum $(\mathrm{Y}+\mathrm{La})$ retained as a function of the height of the casting and the wall thickness. Analysis was performed by a variety of techniques to ensure consistency. Principally, the bulk alloy Y values were evaluated using ICPOES on material removed from the castings. A high concentration of RE reaction products was detected at the cast surface. In order to avoid incorporating the surface reaction products in the bulk alloy concentration, the cast surface was grit-blasted with alumina and cleaned ultrasonically in a $1 \%$ soap solution prior to taking millings from the surface. This surface preparation produced repeatable $\mathrm{Y}$ bulk retention levels that were consistent with more localised analysis techniques using Laser Ablation Inductively Coupled Plasma Mass Spectrometry, (LA-ICP-MS). Initially, multiple samples were taken from specific areas of each mold and at various depths from the surface. However, there was little variation in the bulk retention results, hence the results taken from similar positions were averaged. $\mathrm{Y}+\mathrm{La}$ retention results were compared between solid and silica core containing components in order to show the effect of section thickness and surface area.

\section{Microstructural Analysis}

Analysis of $\mathrm{Y}+\mathrm{La}$ phases doped into CMSX-4 was conducted with a range of optical and micro analytical techniques, to compare $\mathrm{Y}+\mathrm{La}$ phase distribution and their microstructure at specific positions in the cast turbine blades. These include Backscattered Secondary Electron Microscopy BSEM), Energy Dispersive X-Ray Spectroscopy (EDS) Laser Ablation Inductively Coupled Plasma Mass Spectroscopy (LA-ICP-MS), Dynamic Secondary Ion Mas Spectroscopy (DSIMS), Electron Probe Micro Analysis (EPMA) and Transmission Electron Microscopy (TEM) of Focused Ion Beam (FIB) milled extracts.

A range of analytical techniques was required to fully characterize $\mathrm{RE}$ phases and the surrounding microstructure. It is difficult to find RE phases due to their paucity and small size. This was further complicated by their similar appearance and contrast to several phases normally found in CMSX-4. Fortunately $\mathrm{Y}+\mathrm{La}$ phases tend to be located in interdendritic areas next to pores and the phases contain heavy elements such as W, Hf and Ta, that appear bright white in backscattered (BSE) mode in the SEM. Scanning Electron Microscopy SEM/Backscatter imaging was conducted on Camscan MX2600 and Joel 5800 operating at 35 $\mathrm{mm}$ working distance/10 Kev accelerating voltage for imaging and at $10 \mathrm{~mm} / 15 \mathrm{Kev}$ for compositional analysis, by an Oxford Instruments Energy Dispersive X-ray Spectroscopy (EDS). EDS analysis was used to qualitatively identify the elemental composition, as calibration standards for $\mathrm{Y}+\mathrm{La}$ were not available.

\section{TEM and FIB microanalysis techniques}

Due to RE phase scarcity and their small size, it proved very difficult to produce a TEM foil containing a transparent RE phase by thinning the foils using electropolishing techniques. Further problems were encountered due the surrounding matrix selectively thinning without reducing the RE phase sufficiently for TEM analysis. Hence areas of interest of were located in the SEM and lifted out of the alloy using an FEI Helios NanoLab SEM focused ion beam (FIB) milling unit. The exposed RE and S phases were ion beam milled thinning them down to $100 \mathrm{~nm}$. These samples were attached to a TEM slide. TEM was undertaken using JEOL 200CX microscope in a bright-field imaging mode. Selected area diffraction patterns were obtained of RE phases in order to identify the crystal structure.

Phase composition was obtained using EDS in Tecnai F20 FEG TEM EDS Scanning Transmission Electron Microscopy (STEM). Elemental distributions were analysed using DSIMS conducted on a Cameca ims-4f instrument. In chemical imaging mode, utilising a magnetic sector mass spectrometer, it is capable of separating elemental and molecular species by a combination of high mass resolution and/or target bias offset. DSIMS images were acquired using a $10 \mathrm{keV} \mathrm{Cs}^{+}$primary ion beam for -ve secondary ion detection and a $15 \mathrm{keV} \mathrm{O}^{2+}$ beam for +ve ion detection. Beam currents were generally $\sim 1 \mathrm{nA}$ and data acquired from areas of $500 \mu \mathrm{m} \times 500 \mu \mathrm{m}$, or $100 \mu \mathrm{m} \times 100 \mu \mathrm{m}$. The extraction field in the instrument was $+/-4.5 \mathrm{keV}$. Background pressure was $\sim 5 \times 10^{-10} \mathrm{~Pa}$. DSIMS analysis measures the atomic mass of the sputtered material and therefore it was necessary to consider those combinations of ions that can add up to the atomic mass of the element of interest. For example: Ion peaks occur at $\mathrm{Y}^{+}$mass 89 amu and $\mathrm{YO}^{+}$of $105 \mathrm{amu}$. There are no isotopes of $\mathrm{Y}$, which is present entirely at 89 amu. However, other ion cluster combinations may have a similar amu and therefore potentially interfere with spectral analysis. For example cluster ions in the may arise from $\mathrm{NiAl}^{+}$ions. For example the main isotope of $\mathrm{Ni}$ $62(4 \%)+\operatorname{Al}(27)^{+}$also has an 89 amu. Detection of $\mathrm{S}$ at $32 \mathrm{amu}$ required separation from isobaric interferences principally ${ }^{16} \mathrm{O}_{2}$, also at 32 amu. In an attempt to discriminate between these combinations of ions, the DSIMS unit was focused onto the exact atomic mass units of the individual elements and compared with corresponding isotopes where available. This was conducted to ensure the result was genuinely from the element of interest.

\section{Results}

Standard production casting conditions, described above, were used to benchmark the existing zircon mold and silica core materials at a doping level of $1126 \mathrm{ppm}$. The wax template in Figure 1 shows the variety of component shapes cast. Figure 2 shows the \% Y retained through the casting. Samples were analysed from both bulk and surface areas at various heights in the casting, for cored and solid samples, that ranged from $1 \mathrm{~mm}$ up to $20 \mathrm{~mm}$ in thickness.

This first mold cast, showed that $\mathrm{Y}$ losses began to occur during the melting cycle in the aluminosilicate fibre crucible, prior to entering the mold. This showed a relatively high loss of the dopant addition, due to chemical reaction with the crucible lining material and evaporation prior to pouring. The remaining $\mathrm{Y}$ that entered the mold cavity was measured from samples immediately solidifying on the chill plate before it reacted with the refractories 
and before evaporation occurred during the solidification stage, into the main vacuum environment. Analysis of further trials showed that $\mathrm{Y}$ dopant melting losses to the crucible during melting was highest below $750 \mathrm{ppm} \mathrm{Y}$, with an average approximately $30 \%$, with some losses as high as $40 \%$. Higher losses at lower dopant levels were due to insufficient $\mathrm{Y}$ being available to passivate the crucible. Melting losses reduced as the dopant level increased due to higher levels of reaction products saturating the crucible/alloy interface. Y retention, during melting, was also dependent on the method of addition. When $\mathrm{Y}$ was added as a dopant at the end of the melting cycle, prior to pouring, approximately $10 \%$ higher loses occurred. This was due to localised $\mathrm{Y}$ saturation in the alloy, increasing both the reaction rate with the crucible and volatilisation into the vacuum system. Consistently lower losses occurred when the RE additions were pre-homogenised into the barstock prior to melting.

After removal of attached $\mathrm{RE}$ reaction products and the $\mathrm{Y}$ denuded zone immediately below the as-cast surface, the bulk concentration level of $\mathrm{Y}$ was similar at localised cross-section of the components. Similar trends in Y retention occurred in all the shell mold materials tested. The largest effect on the bulk Y concentration at different locations of the mold was due to the section thickness. The thicker solid components had higher retention levels than thinner sections, especially where formed by a silica core. Thicker solid sections located at the top of the mold also tended to have higher $\mathrm{Y}$ retention than expected, despite the alloy being molten longer than alloy solidifying earlier in the casting cycle. This contradiction maybe explained by the RE saturating the refractory reducing the rate of reaction. The thinner silica cored samples exhibited more balanced Y retention levels throughout the component due to having similar section thickness at the top and bottom of the component. The thinnest sections, below $1 \mathrm{~mm}$, formed between the internal silica core and shell mold had the lowest $\mathrm{Y}$ retention, with some samples being almost completely denuded of $\mathrm{Y}$. The largest $\mathrm{Y}$ concentration was typically measured at the top of the pouring cup where excess $Y$ had accumulated by floating out of the alloy during the slow solidification stage or deposited as a slag compound at the end of the pouring cycle.

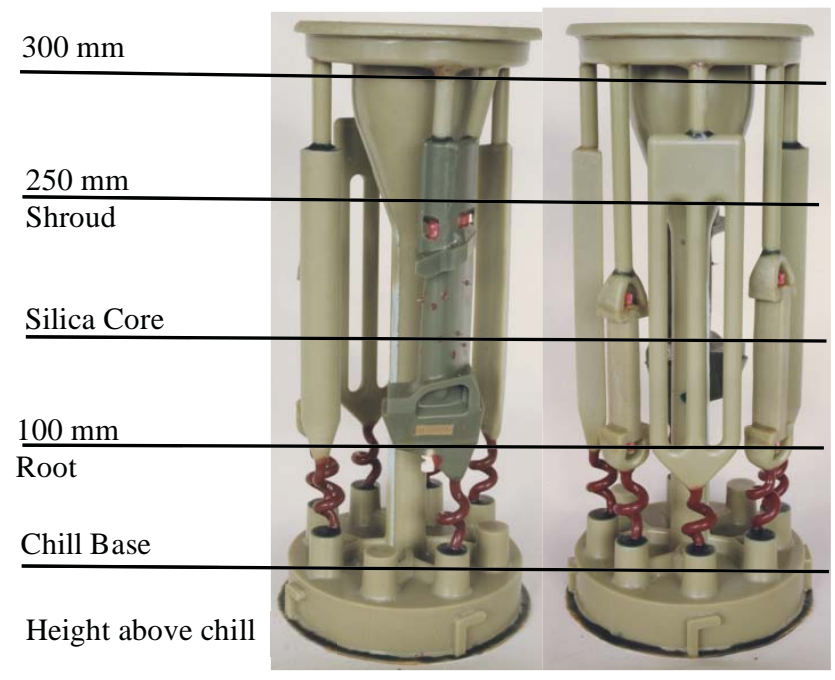

Figure 1: Multi component mold configuration containing representative geometric shapes and section thickness for initial trials to benchmark existing practice.

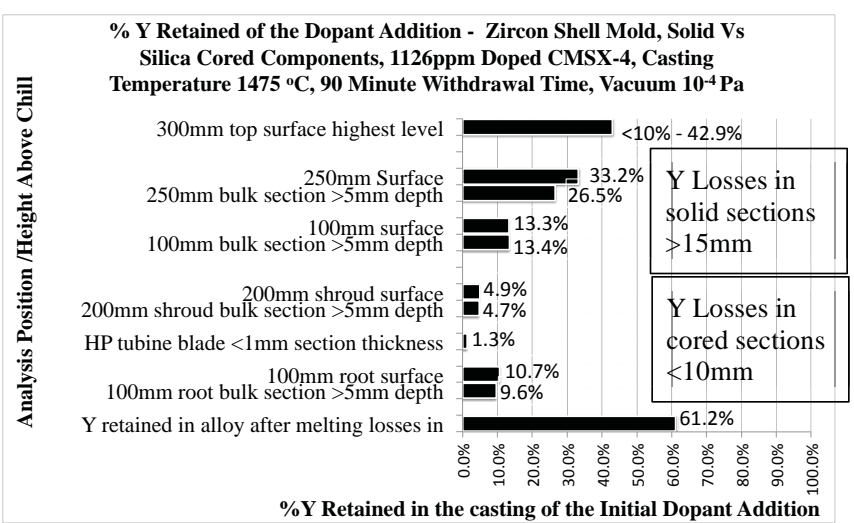

Figure 2: Benchmark losses in zircon shell mold

\section{Y losses due to section thickness}

The Y retention results of inert shell molds are shown in Figure 3, for a range of section thicknesses. These results also show the same trend to the silica/zircon molds with the thicker sections retaining higher levels of $\mathrm{Y}$ compared to thinner sections. This shows that section thickness of the casting has a significant influence on RE losses, whereas the height position above the chill plate, was less significant. A series of castings, were made to probe the effect of thick $(>20 \mathrm{~mm})$, thin $(<5 \mathrm{~mm})$ and cored casting (>2 mm) sections, the doping level was varied within range from $250 \mathrm{ppm}$ to $1100 \mathrm{ppm}$, reflecting the anticipated practical range. Casting parameters were as standard and four mold types were used. These were: zircon, alumina, yttria + alumina mixture and a yttria facecoat.

The results in Figure 3 plotted as a $\%$ of the Y retained from the dopant addition, are consistent with the baseline castings in Figure 2 , showing a retention rate of $\sim 10 \%$ for the silica/zircon mold in thick castings, with double that retained in the alumina and up to five times higher for the yttria molds. However when the thickness is reduced to $5 \mathrm{~mm}$, the advantage of the yttria and alumina molds is much reduced, with all four systems performing at the same level of approximately around $10 \% \mathrm{Y}$ retention. However, in the silica cored sections where the section thicknesses were below $2 \mathrm{~mm}$, the yttria and alumina systems retained about $4-6 \%$ of the dopant, enough to give a $\sim 50+\mathrm{ppm}$ yttrium level in these thin aerofoil sections, whereas the zircon retained around $1 \%$ and indeed, in some cases, none at all was detectable. Alumina performs particularly well at the lower levels of doping, Figure 4.

Effect of yttrium doping level:

A series of $12 \mathrm{~mm}$ bars were cast using three of the mold systems: Silica/zircon, alumina and yttria at the standard conditions. Doping levels varied from $50 \mathrm{ppm}$ to $5000 \mathrm{ppm}$, Figure 4. These results show that, for silica/zircon the percentage $\mathrm{Y}$ retained is very consistent at $10 \%$ of the dopant added up to $2000 \mathrm{ppm}$, despite the large increase in the doping level. This is in line with two previous studies on similar dopant levels; results from Aimone [7] and Ford [8] have been added into Figure 4 and both reported $10 \% \mathrm{Y}$ retention in silica/zircon refractory molds. Above $2000 \mathrm{ppm} \mathrm{Y}$ the silica/zircon begins to passivate increasing the retention level. In comparison, the more inert alumina and yttria refractories show the expected higher $\mathrm{Y}$ retention rate compared with the silica/zircon mold retaining about double the amount of $\mathrm{Y}$ at each dopant levels above $100 \mathrm{ppm} \mathrm{Y}$. 


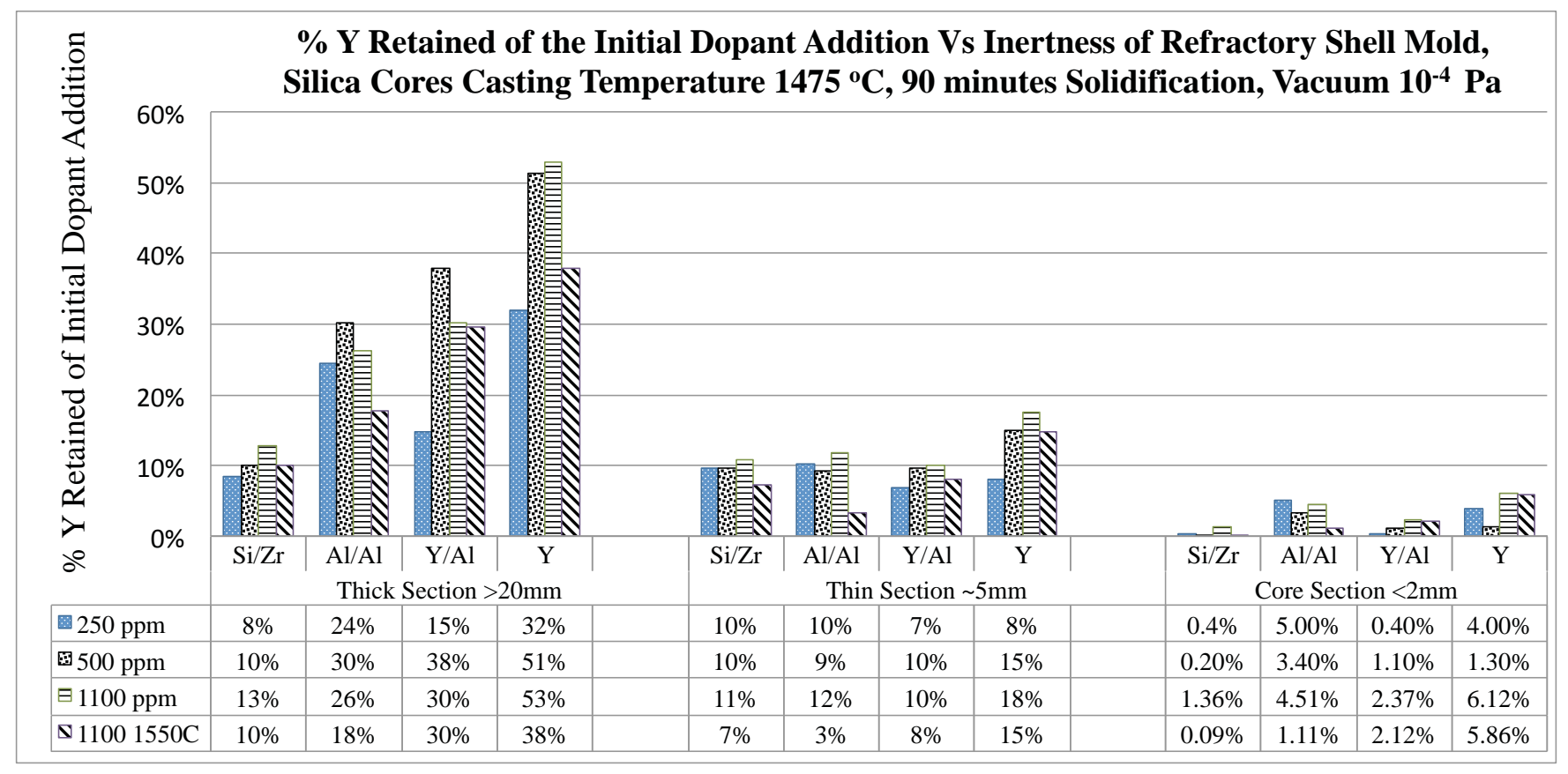

Figure 3: \% Y Retained of initial doping level vs. inert face coat and dopant level using ICP OES after removal of $\sim 200 \mu \mathrm{m}$ of the as-cast surface.

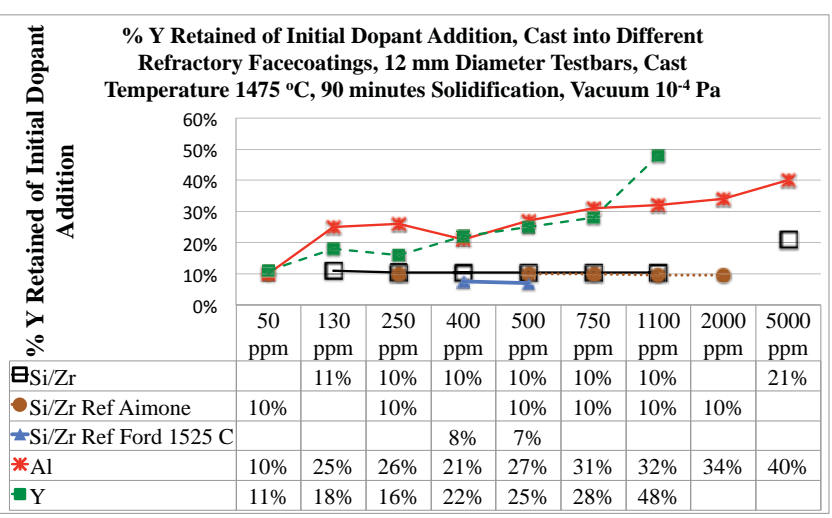

Figure 4: Retention level as a percentage of initial doping level.

At doping levels $<750 \mathrm{ppm} \mathrm{Y}$, there is little difference in $\mathrm{Y}$ retention levels in the alumina and yttria shell molds. The curves in Fig 4 show some interesting trends in terms of the mechanism of loss. If the loss to the mold in these thick-sectioned bars were controlled by diffusion in the bars themselves, and the mold acted as a constant sink for the $\mathrm{Y}$, one would expect this loss to scale with substrate concentration, absorbing all the available $\mathrm{Y}$ from the alloy, giving a consistent $\%$ retention. This is seen most clearly in the data for the silica/zircon mold. Where the capacity of the mold material immediately adjacent to the metal to absorb the $\mathrm{Y}$ becomes compromised, either by chemical change, or saturation through lack of transport away from the surface, the amount lost will decrease as the doping level rises. The alumina mold being more inert absorbs less Y from the alloy, but $\mathrm{Y}$ losses continue at the same rate and appear not to become saturated even at the $5000 \mathrm{ppm}$ dopant level. Saturation of the refractory mold can be seen in the yttria mold, where the Y losses rapidly decrease above the 750 ppm dopant level.

\section{Losses due to casting parameters}

Vacuum levels: The effect of vacuum was investigated by casting test bar molds in a lower vacuum than the standard production level, [9]. The effect of a 10 times increase in pressure, from the standard pressure of $1 \times 10^{-4} \mathrm{~Pa}$ to $1 \times 10^{-3} \mathrm{~Pa}$, doubled the retained $\mathrm{Y}$ from $11 \%$ to $23 \%$ in the silica/zircon mold and showed similar trends cast in the other inert mold materials, Figure 5. This is consistent with a vapour pressure for $\mathrm{Y}$ of $3.52 \times 10^{-3} \mathrm{~Pa}$ at $1550{ }^{\circ} \mathrm{C}$ of $10^{-4} \mathrm{~Pa}$ Therefore, reducing the vacuum level to the minimum possible without causing the alloy to oxidize would increase $\mathrm{Y}$ retention rates.

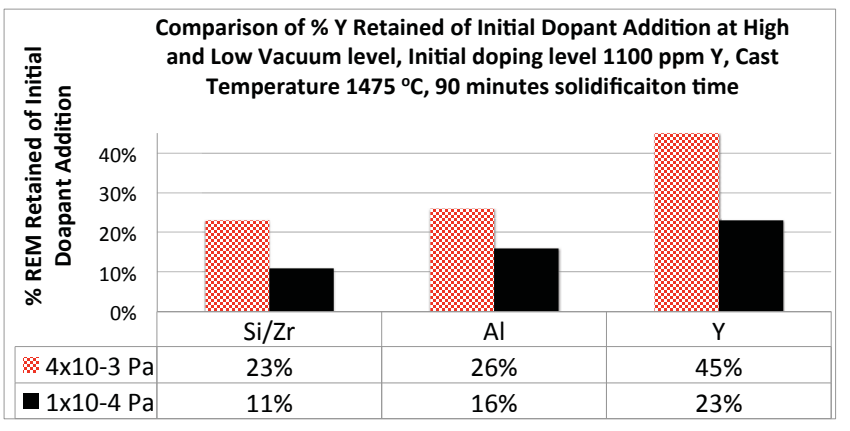

Figure 5: Comparison of the $\% \mathrm{Y}$ retained of the initial dopant addition at two casting vacuum levels; $4 \times 10^{-3} \mathrm{~Pa}$ to $1 \times 10^{-4} \mathrm{~Pa}$.

Effect of solidification time: The effect of the time the molten alloy was contact with the mold was investigated by cooling the molds in less than 5 minutes after casting. This showed that a high proportion of the losses had already occurred immediately after the pouring cycle, Figure 6 . Higher losses occurred when the alloy was slowly cooled at the standard withdrawal rate for single crystal casting with a total withdrawal time of 90 mins (corresponding to a withdrawal rate of $2.2 \mathrm{~mm} \mathrm{~min}^{-1}$ ). Increased 
losses occurred when the solidification time was extended to 120 minutes by slowing down the solidification rate. This showed that either the refractories had not become saturated or Y continued to be lost to the dynamic vacuum system within casting chamber.

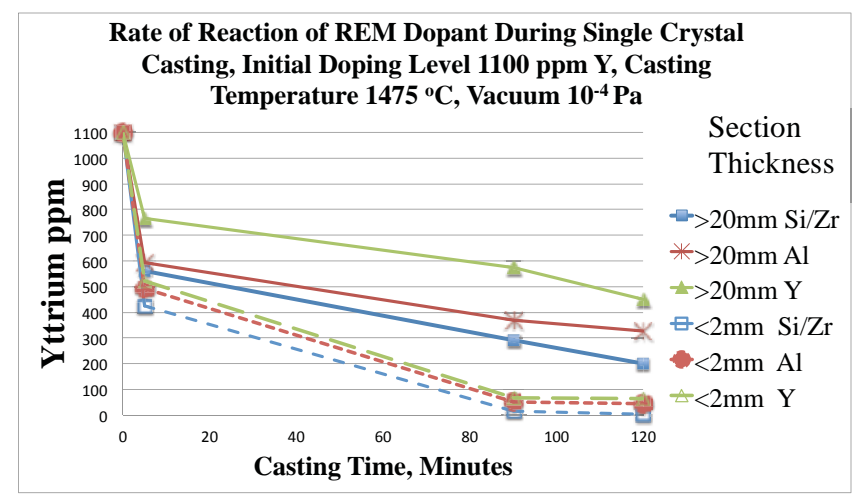

Figure 6: Effect of solidification time on Y retention in different shell mold refractories

Effect of casting temperature: Castings were made of $12 \mathrm{~mm}$ bars at two temperatures; the standard $1475{ }^{\circ} \mathrm{C}$ and at an elevated temperature of $1550{ }^{\circ} \mathrm{C}$. The results of the retention levels in the four mold materials are given in Figure 3 at different section thickness and $12 \mathrm{~mm}$ test bars in Figure 4b. The higher casting temperature consistently causes a significantly more of $\mathrm{Y}$ loss in all section thicknesses and molds due to higher reaction rates at higher temperatures with the shell refractories and higher volatilization rates to the vacuum system.

\section{Summary of losses during casting}

Losses of the Y dopant during casting are severe but quantifiable. They come from a limited number of sources. Up to $40 \%$ of the $\mathrm{Y}$ is lost before the metal enters the mold, either to the crucible or through evaporation. The level of the vacuum has an important effect; losses increasing as the vacuum improves. The amount of $\mathrm{Y}$ retained in the bulk sections of the castings in a zircon mold system was consistently around $10 \%$ at all dopant levels although higher levels were observed towards the top of the thicker solid casting in the original benchmarking trials. However, in the thin sections where the metal thickness is between 1-2 mm, losses were severe and the amount of $\mathrm{Y}$ retained was typically $1 \%$ of the initial doping content and in some cases lower. With a starting level of $1100 \mathrm{ppm}$ these sections do not retain enough Y to protect against the effects of current $\mathrm{S}$ levels, but may be sufficient for super low sulphur alloys in the future. The height above the chill plate, scaling with time the molten alloy was in contact with the mold, was a much less important factor than section thickness, particularly in the cored castings. The highest loss rate was immediately after the alloy entered the mold, slowing down as reaction products formed at the shell mold/alloy interface. Further Y losses occurred even at the highest dopant levels due to continuous evaporation into the vacuum system. As expected from their higher inertness, the alumina and yttria shell mold refractories showed approximately double the $\mathrm{Y}$ retention compared to zircon, under similar casting conditions below the $1100 \mathrm{ppm}$ Y doping level. The yttria mold refractory appears to be saturating at levels above $750 \mathrm{ppm}$, whereas the alumina and silica/zircon molds do not show significant saturation until higher levels. It is noticeable that the yttria mold shows rather lower levels of retention at low doping levels than alumina, raising questions as to what exactly is the mechanism by which these materials absorb the $\mathrm{Y}$ from the casting. At RE doping additions below $100 \mathrm{ppm}$, in the presence of silica cores, there was insufficient $\mathrm{Y}$ available in any of the refractory systems tested to pacify the refractories before significantly depleting the alloy of $\mathrm{Y}$ and thus very little $\mathrm{Y}$ was retained in the alloy after casting.

During these trials the yttria refractories posed significant problems in processing due to their instability as a shell mold slurry. This required constant chemical stability adjustment to prevent premature gelling. Additional ceramic sintering of the alumina and yttria refractories was required compared to the standard silica materials in order to achieve consistent results and casting process quality results.

\section{Distribution of RE phases}

In this section we look at the distribution, size and chemical structure of RE dopants Y+La. Lanthanum was added as a second dopant to CMSX-4 [10] for the metallurgical analysis samples. These RE phases were identified at all stages of single crystal casting production (the original barstock prior to melting, as-cast and after heat-treatment), and at various doping levels, including the undoped alloy.

Alloy samples with a low dopant retention of $\mathrm{Y}+\mathrm{La}$ of $30 \mathrm{ppm}$ were taken from turbine blade casting aerofoils and compared to significantly higher dopant level of 1367 ppm Y+La taken from thicker sections of test bars. At the lower dopant level it was particularly difficult to locate RE phases due to their paucity, whilst they were more abundant at the higher dopant level. The results reported represent both low and high dopant levels, as the phases proved to be similar in chemistry and size at all concentrations. Generally, the REs were located in the interdendritic areas because REs have extremely low solubility in the $\gamma / \gamma^{\prime}$ matrix. Hence REs are located in clusters in the last liquid to solidify and are predominantly located adjacent to interdendritic pores that are created when there is insufficient material to fill the volume between the solidified dendrites. Zhou [11] reported that at extremely high dopant levels, it is possible to form RE phases in the dendrites, but none were observed in the CMSX-4 samples tested in this study. Up to $1 \mathrm{ppm} \mathrm{Y+La} \mathrm{was}$ dispersed in the surrounding matrix after heat treatment, detected using DSIMS and confirmed by Laser Ablation ICP-Mass Spectroscopy. The retained levels of $\mathrm{Y}$ tended to be higher than La relative to their dopant level. This was thought to be due to increased losses of the more volatile La.

\section{Location of RE clusters}

DSIMS proved to be the most effective technique for locating the REs on the dendritic scale. Figure 7 shows the DSIMS maps of the distribution of the elements $\mathrm{W}, \mathrm{Ta}, \mathrm{Y}, \mathrm{La}, \mathrm{S}$ and $\mathrm{P}$ in the barstock, as-cast and heat treated microstructures. The relatively fine dendritic structure resulting from the fast cooling of the barstock is apparent, as is the considerable homogenization achieved in the heat-treated structure. This leaves discrete clusters in the interdendritic regions, as identified by the segregation of $\mathrm{W}$ and $\mathrm{Ta}$, to the dendritic and interdendritic regions respectively. Generally the locations of the $\mathrm{Y}+\mathrm{La}$ coincide but with some variation in intensity. The $\mathrm{S}$ shows a preference for the $\mathrm{Y}$ forming $\mathrm{Y}_{2} \mathrm{O}_{2} \mathrm{~S}$ whilst $\mathrm{P}$ tends to combine with $\mathrm{La}$ forming $\mathrm{LaP}$.

The as-cast surface of a Y+La doped CMSX-4 tended to have an enriched layer of RE chemical reaction products at the as-cast surface, as shown in Figure 8. This reaction layer forms due to the 
RE located close to the surface rapidly diffusing to the shell mold/alloy interface during the solidification phase of casting forming a RE rich surface. These RE products are predominantly RE-oxides created by reactions with the refractory oxides. The quantity of reaction products increases in proportion to the dopant level. At lower dopant levels there is relatively little RE surface reaction product, as shown in the DSIMS analysis of the as-cast sample containing $20 \mathrm{ppm} \mathrm{Y}+\mathrm{La}$, Figure 9. The DSIMS map shows a small $\mathrm{Y}+\mathrm{La}$ phase cluster surrounded by a background level of $\mathrm{Y}+\mathrm{La}$ of approximately $1 \mathrm{ppm}$. However, at lower dopant levels there is less $\mathrm{Y}+\mathrm{La}$ available close to the as-cast surface, in this case at $20 \mathrm{ppm} \mathrm{Y}+\mathrm{La}$. Virtually all of the available $\mathrm{Y}+\mathrm{La}$ had diffused to the surface from a depth of approximately $50 \mu \mathrm{m}$ adjacent to the cast surface. This creates a denuded zone of RE at the as-cast surface. At higher dopant levels the surface reaction products increase, but the volume immediately below the surface has a lower RE content similar to the lower doped materials. The distribution of $\mathrm{P}$ and $\mathrm{S}$ overlays show that there is insufficient $\mathrm{RE}$ dopant to getter all the free $\mathrm{S}$, and therefore the free $\mathrm{S}$ can diffuse to the scale/metal interface when subjected to high temperature oxidation environments. The absence of $\mathrm{Y}+\mathrm{La}$ at the surface may account for lower scale/metals adhesion during high temperature oxidation, until the metal regression reaches the areas containing RE phases [12].

1600 ppm Y+La doped CMSX-4 Barstock - all scan areas $500 \mu \mathrm{m}$ x $500 \mu \mathrm{m}$
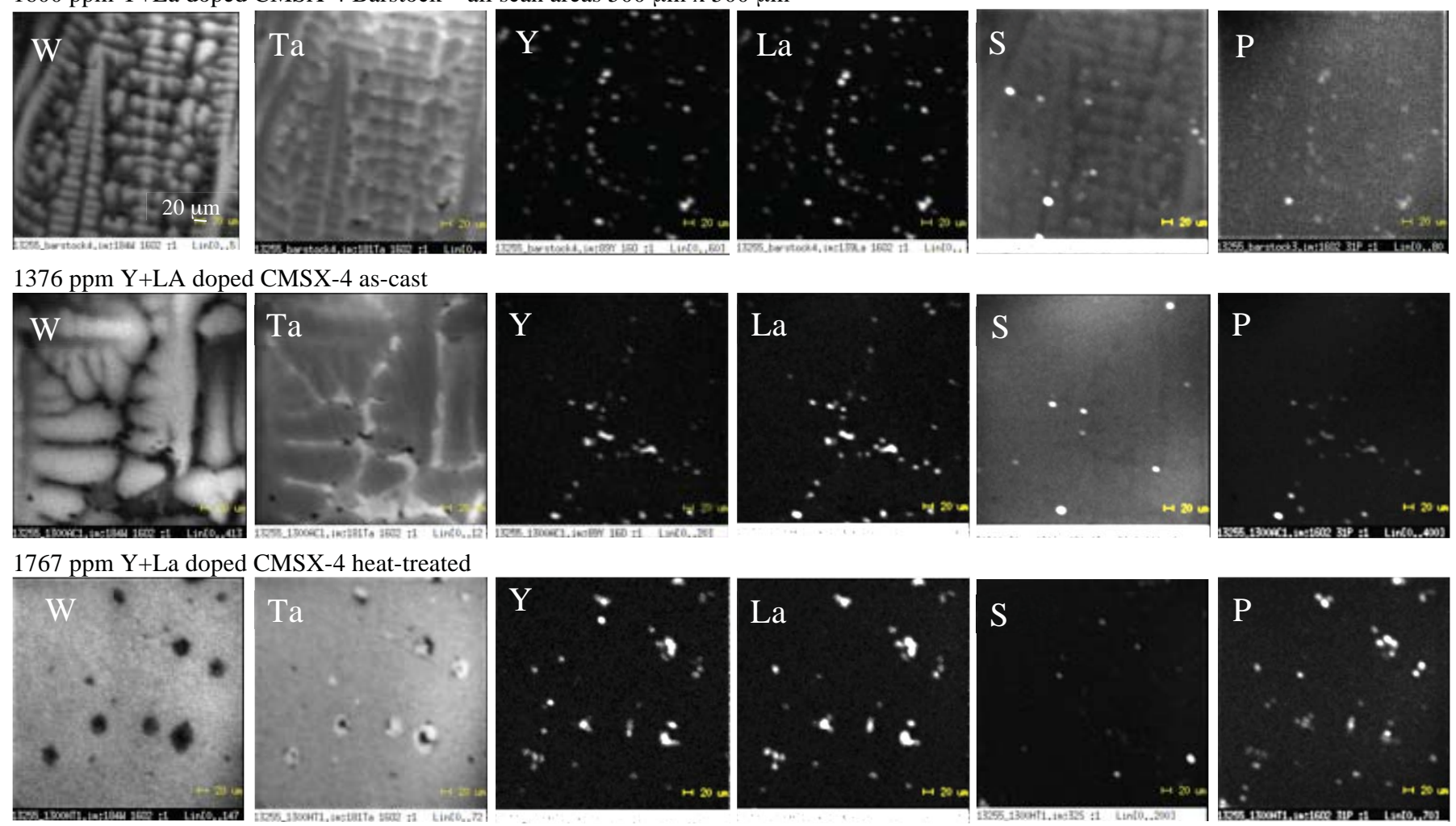

Figure 7: DSIMS maps of the elements W, Ta, Y La S and P for Barstock, as-cast and fully heat treated CMSX-4

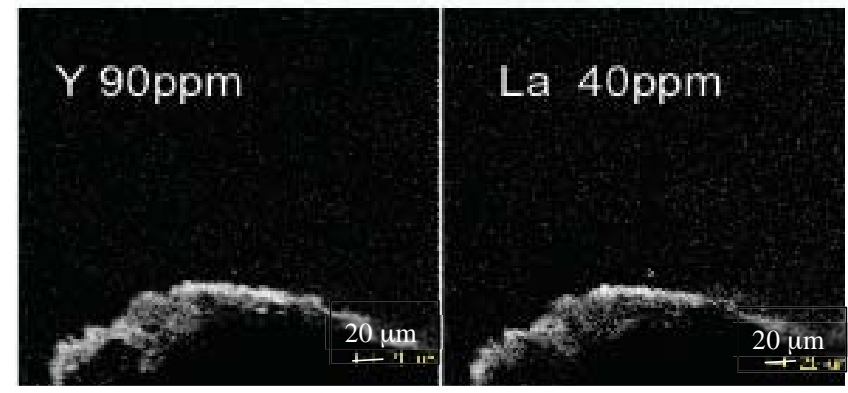

Figure 8: DSIMS image of $\mathrm{Y}+\mathrm{La}$ reaction products formed on the surface of casting prior to surface treatment. CMSX-4 doped with $1367 \mathrm{ppm} \mathrm{Y}+\mathrm{La}, 130 \mathrm{ppm} \mathrm{Y}+\mathrm{La}$ retained after casting

In undoped CMSX-4, only phases rich in tantalum were seen composed of a highly facetted phase, TaC, appearing bright in a backscattered image with a lighter grey phase adjacent, identified as $\mathrm{Ni}_{3} \mathrm{Ta}$. These two phases were also a major component of the RE doped material where the additional phases $\mathrm{Ni}_{5} \mathrm{Y}$ or $\mathrm{Ni}_{5} \mathrm{La}$ were also present and occasionally the somewhat elusive $\mathrm{S}$ and $\mathrm{P}$ containing phases of $\mathrm{Y}_{2} \mathrm{O}_{2} \mathrm{~S}$ and $\mathrm{LaP}$.

The REs are located in the interdendritic regions, principally in small intermetallic cluster that rarely exceed $20 \mu \mathrm{m}$ at lower concentrations increasing up to $40 \mu \mathrm{m}$ at higher dopant levels. Phases in the RE clusters differ within any one sample, and examples are shown in Figures 10 to 16, showing both single and multi-phase examples with small bright and dark precipitates embedded in the $\mathrm{Ni}_{5} \mathrm{Y}$ phase, The $\mathrm{S}$ and $\mathrm{P}$ phases rarely exceed 1-2 $\mu \mathrm{m}$. No systematic pattern emerged at all stages of the production route and it is possible that the different appearance is a result of viewing at different sections. Only the abundance of clusters changed, as the RE concentration changed. 

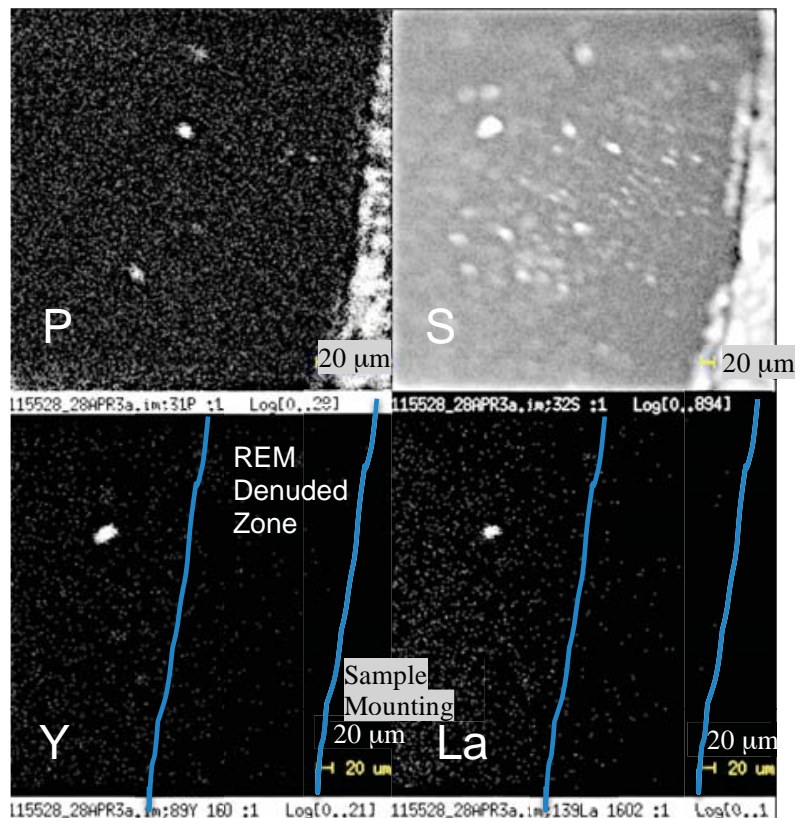

Figure 9 DSIMS image P, S, Y and La showing a RE denuded zone close to cast surface. CMSX-4 doped with $260 \mathrm{ppm} \mathrm{Y+La,}$ $20 \mathrm{ppm} \mathrm{Y}+\mathrm{La}$ retained after casting.
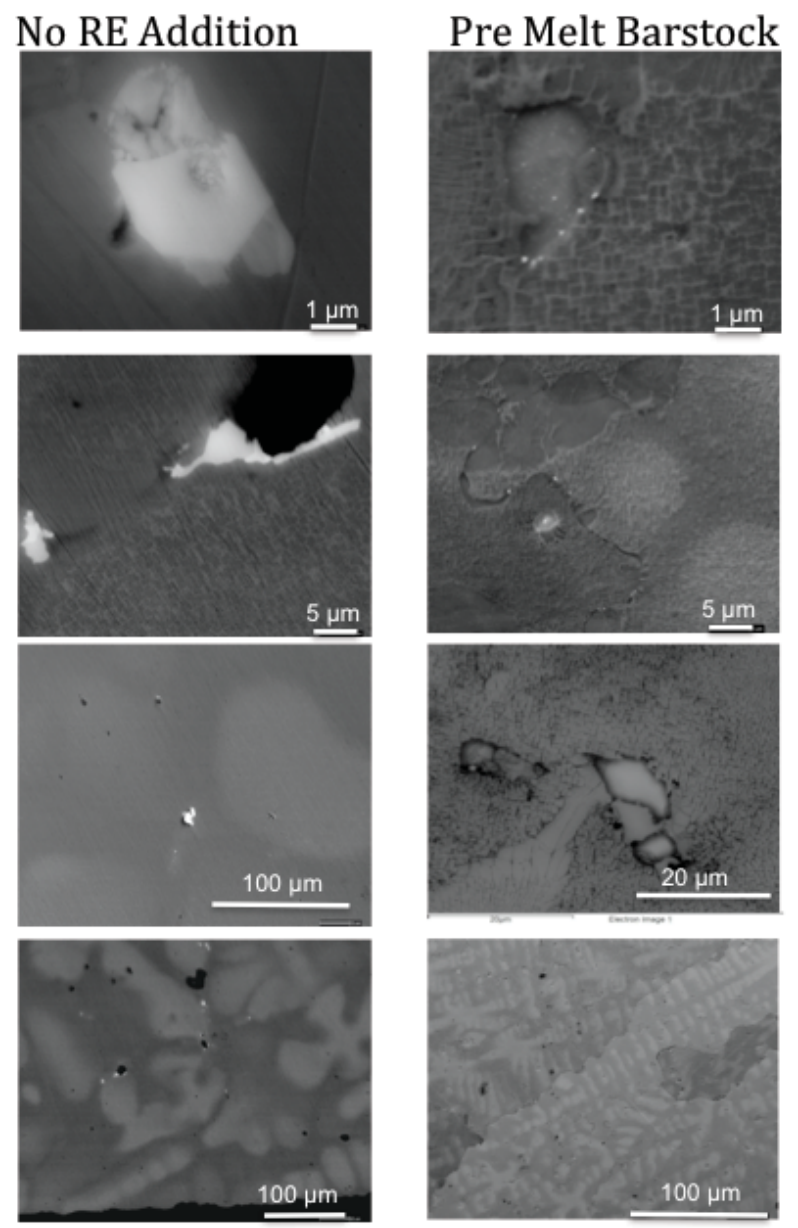

Figure 11: SEM-backscattered images of RE-containing clusters throughout the production cycle of Y and La doped CMSX-4.
Phases in the highly segregated barstock, in line with the small dendrite size as shown in Figure 10, are relatively small, due to being drawn from a smaller solidifying volume. Here $\mathrm{Ni}_{3} \mathrm{Ta}$, $\mathrm{Ni}_{5} \mathrm{Y}$ and $\mathrm{Y}_{2} \mathrm{O}_{2} \mathrm{~S}$ are identified.

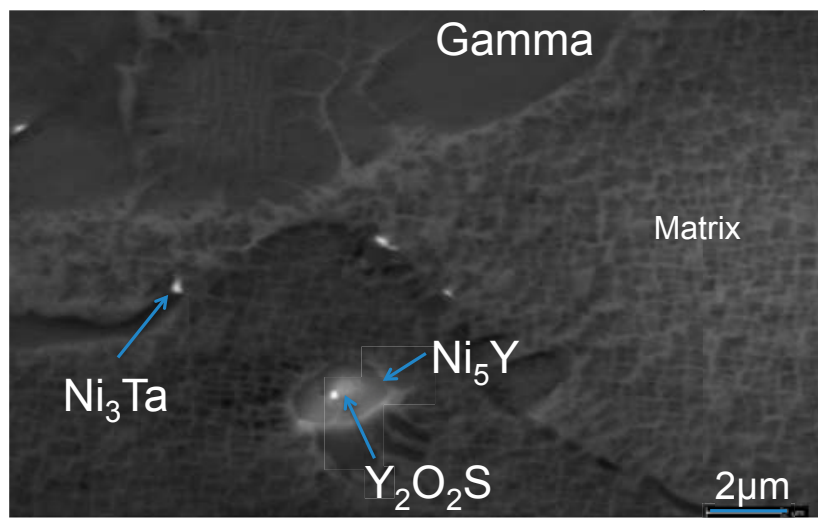

Figure 10 SEM-backscattered image of interdendritic phases in 1600 ppm Y +La barstock.

In Figure 11, the phases are identified in undoped, $1600 \mathrm{ppm}$ Y+La doped barstock, as-cast and heat-treated material doped at 1367 ppm Y+La. 12a, shows a highly facetted TaC, surrounded by the $\mathrm{Ni}_{5}(\mathrm{Y} / \mathrm{La})$ and the phase that getters the sulphur, $\mathrm{Y}_{2} \mathrm{O}_{2} \mathrm{~S}$. The LaP phase is also shown in Figure $12 \mathrm{~b}$.
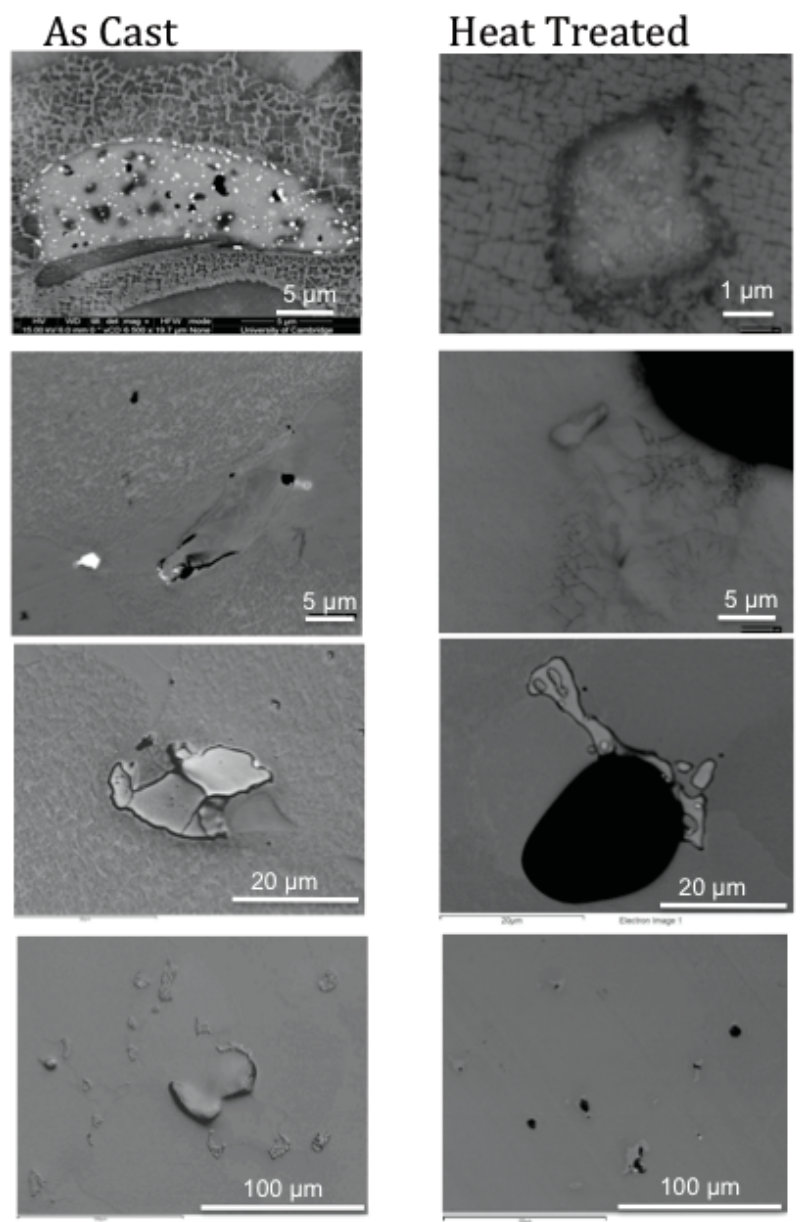
In Figure 13 we show an example of the multi-phase morphology in the heat-treated material. Here the $\mathrm{Ni}_{5} \mathrm{Y}$ phase forms the pale grey central phase dotted with bright $\mathrm{Ni}_{3} \mathrm{Ta}, \mathrm{TaC}$ carbides or $\mathrm{Y}_{2} \mathrm{O}_{2} \mathrm{~S}$ phases and darker $\gamma$ phases. It is surrounded by the characteristic flower morphology associated with incipient melting. Small areas of the $\mathrm{Ni}_{5} \mathrm{Y}$ phase lie at the edges of the melted area.

$\mathrm{Y}+\mathrm{La}$ predominantly form $\mathrm{Ni}_{5}(\mathrm{Y}, \mathrm{La})$ in nickel base alloys, however $(\mathrm{Y}, \mathrm{La})_{2} \mathrm{O}_{2} \mathrm{~S}$ can also form in the presence of $\mathrm{S}$, Figure 14. A yttrium-sulphide phase was identified, Figure 15. A LaP phase is shown in Figure 16.

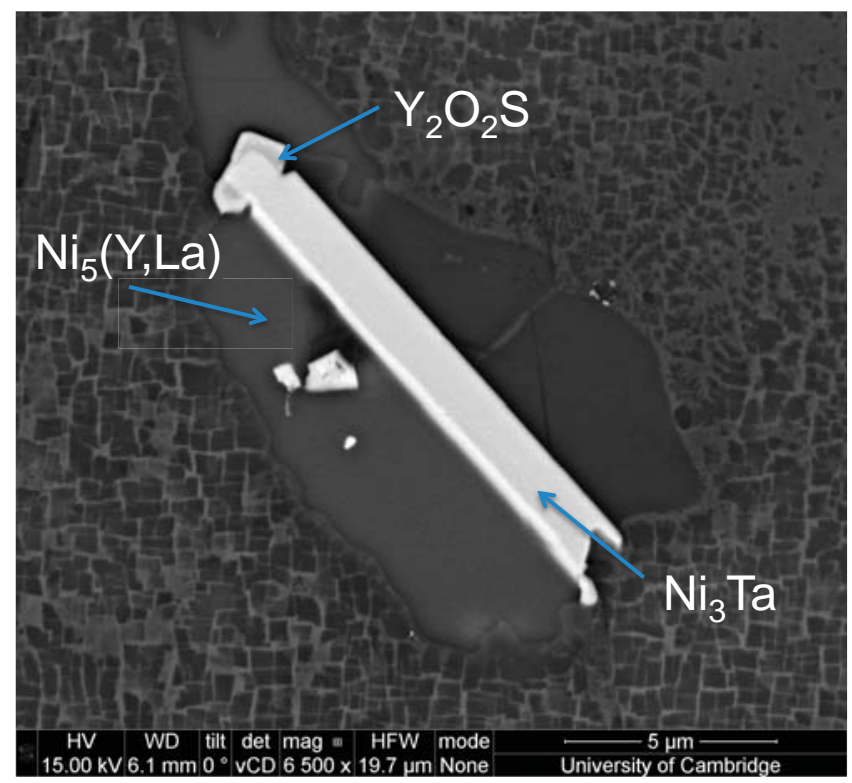

Figure 12 a): SEM-backscattered image of as-cast CMSX-4 doped with 1367 ppm Y+La (subject of FIB section).

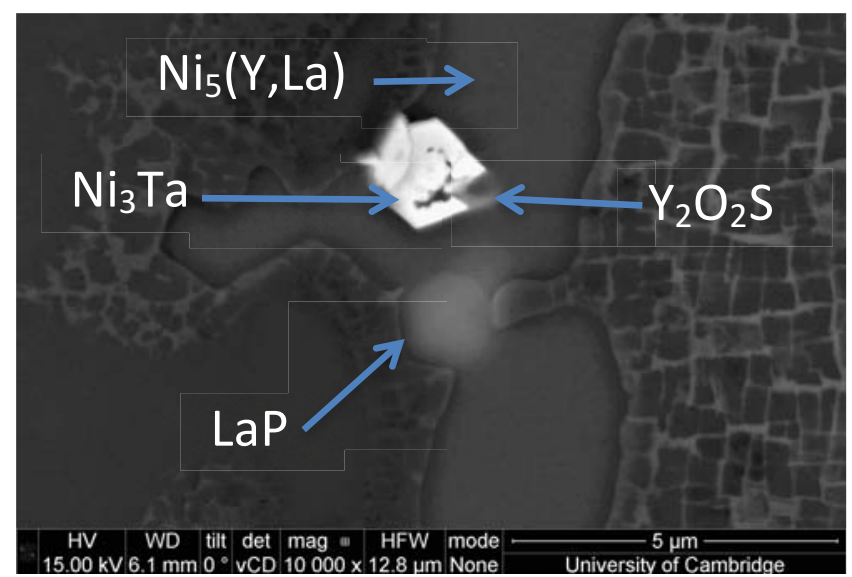

Figure 12 b): SEM-backscattered image of as-cast cast CMSX-4 doped with 1367 ppm Y+La

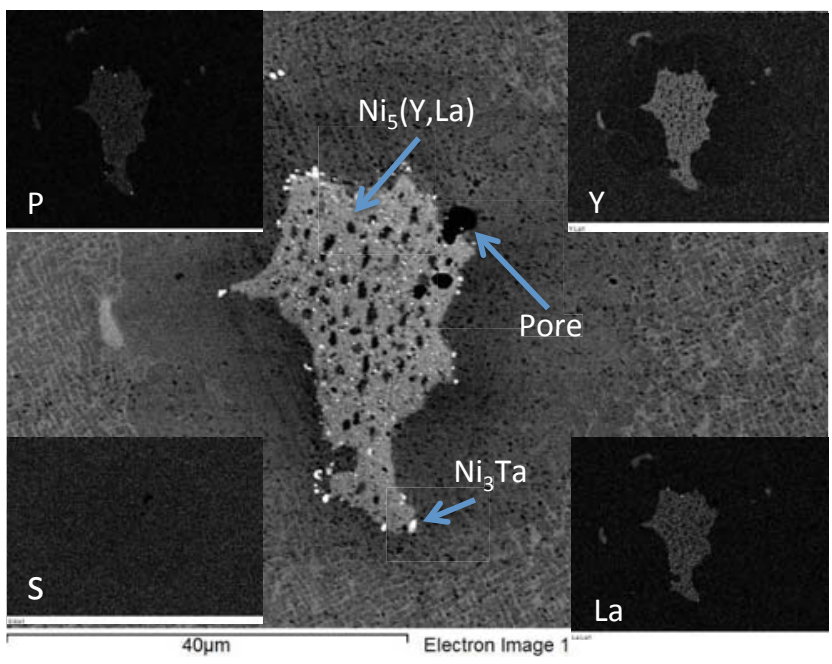

Figure 13: SEM-backscattered image and EDS maps of a multi phased $\mathrm{Y}+\mathrm{La}$ phase cluster, $\mathrm{S}$ and $\mathrm{P}$ in heat-treated CMSX-4 $\rightarrow$ doped with 1367 ppm Y+La

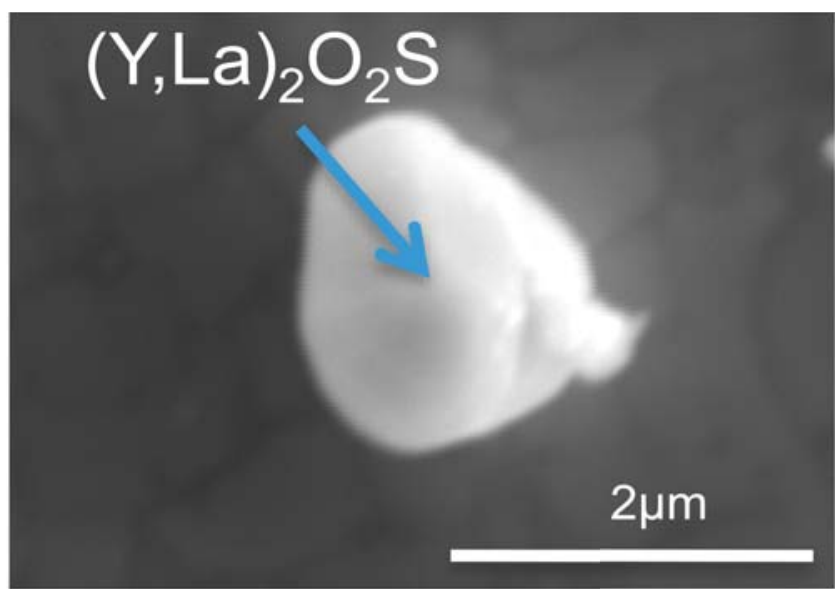

Figure 14: SEM-backscattered image $(\mathrm{Y}, \mathrm{La})_{2} \mathrm{O}_{2} \mathrm{~S}$ phase in CMSX-4 doped with 1367 ppm Y+La

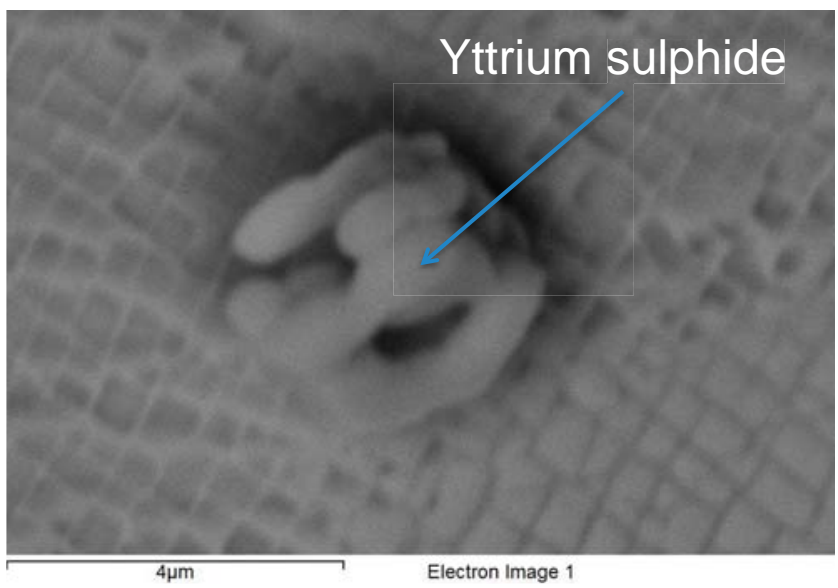

Figure 15: SEM-backscattered image of a yttrium-sulphide phase in CMSX-4 doped with 1367 ppm Y+La 


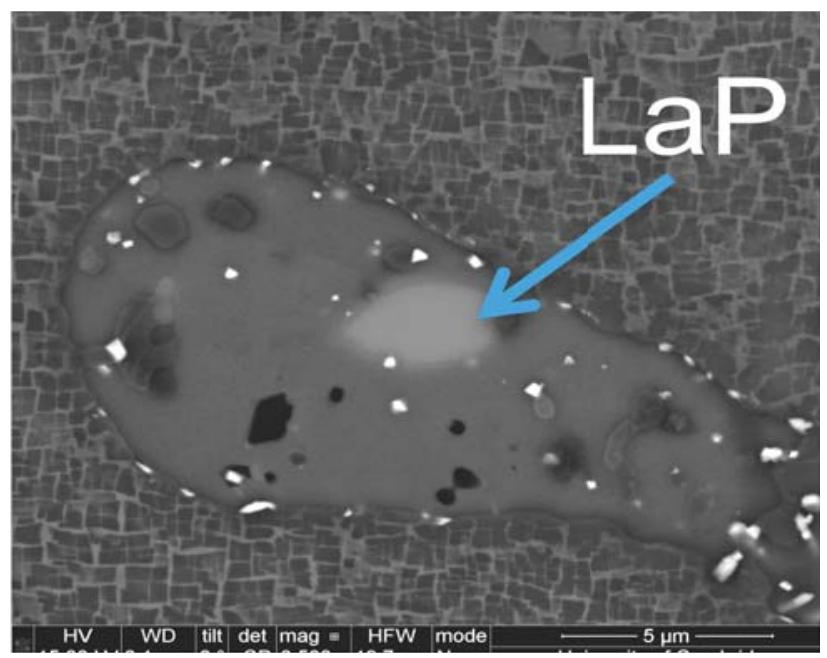

Figure 16: SEM-backscattered image LaP phase in CMSX-4 doped with $1367 \mathrm{ppm} \mathrm{Y+La}$

\section{TEM identification of the cluster phases}

Several of the clusters were sectioned via conventional electropolishing and FIB milling, in order to identify the crystallography of the phases and confirm their structure. Fuller details of the analysis will be published elsewhere, but phases positively identified include the $\mathrm{Ni}_{3} \mathrm{Ta}, \mathrm{TaC}, \mathrm{Ni}_{5} \mathrm{Y}, \mathrm{Y}_{2} \mathrm{O}_{2} \mathrm{~S}$ and LaP. In each case at least three low index poles were imaged for each precipitate identified and the crystal structures confirmed were as follows. Ta was identified in two forms: Monoclinic P1 $21 / \mathrm{m} \mathrm{Ni}_{3}$ Ta phase and as carbide FCC Fm $\overline{3} \mathrm{~m}$ TaC phase in the presence of $\mathrm{C}$. $\mathrm{Ni}_{3} \mathrm{Ta}$ formed a facetted interface with the adjacent hexagonal $\mathrm{P} 6 / \mathrm{mmm} \mathrm{Ni}_{5}(\mathrm{Y}, \mathrm{La})$ phase indicating a strong orientation relationship between the phases that has been investigated in the similar system $\mathrm{Mg}_{2} \mathrm{Zn} / \mathrm{Mg}_{4} \mathrm{Zn}_{7}$, [13]. La was absent from the $\mathrm{Y}_{2} \mathrm{O}_{2} \mathrm{~S}$ phase identified in the microstructure of CMSX-4 as Triganol P-3m1, Figure 15, and La was identified as Cubic - FCC Fm $\overline{3} \mathrm{~m}$, and also as the LaP phase showing that $\mathrm{La}$ had a strong affinity for P, Figure 16 .

\section{Discussion}

RE dopants are more reactive than traditional superalloy elements, and require more attention to the reaction rates in the casting process. In order to use RE additions effectively it is essential not only to know how much RE dopant to add to the alloy, but to understand where and when the losses occur, so that components and casting technology can be optimized to retain sufficient levels of REs, in critical locations. The subsequent supply of REs to provide continued high temperature oxidation protection throughout service depends on the nature and distribution of RE reservoirs in the microstructure [14]. RE dopants react not only with $\mathrm{S}$ and $\mathrm{O}_{2}$ during the casting cycle, but with other tramp elements notably and P, with La forming LaP. Aimone [7] argued that the alloy required a RE:S ratio of $6: 1$ in order to getter the free $S$. Therefore the initial dopant level required would be approximately 60:1, RE:S, enough to getter all free $S$, relative to the impurities present in the alloy, inertness of the mold refractories and rate of volatilization.

It was established that RE dopant losses are dependent on the casting conditions required to make turbine blades, including casting temperature, solidification time, vacuum levels, surface area to volume ratio; with the main factor being the section thickness of the casting. Understanding the reaction mechanisms that affect RE losses will allow the casting engineer to calculate and achieve a target RE retention level in the cast component, without over doping the thick sections and under doping the thin aerofoil blade sections. It is also proposed that the highly reactive silica cores used to form thin walled castings need to be replaced with more inert refractories to reduce the retention difference between the thick and thin sections of the turbine blades.

$\mathrm{RE}$ losses reported in this work showed that approximately $30 \%$ to $40 \%$ of the initial dopant addition reacted with the crucible before entering the investment mold. The remaining RE available reacted immediately upon contact with the mold face-coat refractory. The choice of shell mold and internal core refractory will directly influence RE loss rates, due to varying levels of inertness. For $12 \mathrm{~mm}$ section thickness bars, this work has shown that a further $50 \%$ of the initial dopant addition reacted with the refractories or vapourized within the first 5 minutes of casting. After the initial reaction on pouring, the loss rate slowed during the remaining solidification cycle due to pacification of the refractories. The rate of RE loss during the casting cycle followed the predicted inertness of the shell mold refractories:

$$
\text { Silica/zircon < alumina, < alumina/yttria, < yttria. }
$$

The majority of the RE had been absorbed into the shell mold during casting [8], whilst the remaining losses were to the vacuum system. In agreement with Aimone [7] and Ford [8], $10 \%$ dopant retention occurred in the silica/zircon shell molds. These RE retention results from different alloys, cast in different casting processes, confirm that the rate of reaction was dependent largely on the reactivity of silica/zircon refractories. This work has shown a higher retention of $20 \%$ in alumina and yttria casting refractories. RE retention depend on the section thickness, especially when in contact with a silica core in the blade aerofoil sections. Therefore, the advantage of the higher inertness of alumina and yttria face-coats was diminished by the high reactivity of the silica core. It has also been shown that in thin sections, losses from the $50 \mu \mathrm{m}$ closest to the cast surface are particularly severe. Hence the surface to volume ratio is a key design parameter. RE retention levels were more predictable below a doping level of $500 \mathrm{ppm}$. Therefore, the lower RE retention level target required in super low sulphur alloys would also be more controllable and achievable.

Comparing Y+La doped to undoped microstructures of CMSX-4, it was observed that the undoped alloy had similar dendritic cores with Ta rich phases, $\gamma / \gamma^{\prime}$ eutectic and gross $\gamma$ phases in interdendritic areas. $\mathrm{S}$ and $\mathrm{P}$ were more dispersed throughout the undoped microstructure without the gettering effect of RE dopants. In the rapidly cooled barstock the clusters are smaller and more closely spaced than in the as-cast microstructure, reflecting the smaller dendritic volume from which the insoluble elements are rejected.

REs have low solubility in both liquid and solid states, partitioning to the liquid phase in order of melting point and energy of formation, forming discrete intermetallic phases during solidification where they encounter other insoluble elements such as $\mathrm{S}$ and $\mathrm{P}$. RE phases were more abundant at higher concentration levels, but their size was restricted to the space between the solidifying dendrite arms, rarely exceeding $20 \mu \mathrm{m}$ at low concentrations and $40 \mu \mathrm{m}$ at higher concentration. The $\mathrm{S}$ and $\mathrm{P}$ phases were rarely larger than $2 \mu \mathrm{m}$. Due to the large difference in atomic radii of REs, and other interdendritic elements, four 
specific phases predominantly form: $\mathrm{Ni}_{3} \mathrm{Ta}$ (monoclinic) or $\mathrm{TaC}$ (FCC) in the presence of $\mathrm{C}, \mathrm{RE}_{5} \mathrm{Y}$ (Hexagonal), $\mathrm{Y}_{2} \mathrm{O}_{2} \mathrm{~S}$ (Trigonal) and $\mathrm{LaP}$ (FCC). All four types of phases were present in each of the three alloy conditions. However, the $\mathrm{Ni}_{3} \mathrm{Ta}$ phase tended to be less abundant after heat treatment, but was still present in small quantities. Single structure phases and multi-phase clusters were present in the all the RE sample conditions.

The microanalysis techniques used indicated that there was an association of $\mathrm{Y}+\mathrm{La}$ with $\mathrm{S}$ and $\mathrm{P}$, however not all the RE phases contained $\mathrm{S}$ and $\mathrm{P}$. There was no Y+La detected in the $\gamma / \gamma^{\prime}$ phases, or in the dendrite core before heat-treatment. After heat treatment, Y+La was also detected in the bulk matrix, albeit at a very low level, too low to provide protection on its own, but $\mathrm{S}$ and $\mathrm{P}$ remained tied up in the RE phases.

In agreement with other workers [15], a RE depletion zone was detected up to $50 \mu \mathrm{m}$ below all the cast and heat-treated sample surfaces analysed. This correlates closely with the observation that although losses from section thicknesses of $5 \mathrm{~mm}$ are similar to thicker sections. Once the thickness reduces below $2 \mathrm{~mm}$, the retention levels drop from $10 \%$ to $<1 \%$ and in some cases below a detectable level. The surface to volume ratio of the cast component is therefore a significant factor when calculating $\mathrm{RE}$ retention.

\section{Conclusion}

The objectives of this study were achieved, firstly identifying the key process parameters that affect RE losses during single crystal casting and secondly, characterising the phases partitioning to interdendritic areas of CMSX-4. This work showed that RE losses increased at higher temperatures and higher vacuum levels due to increased reaction with the refractories and an increased vapourisation rate. Selection of refractories with the highest inertness reduces dopant losses. Higher losses occur in thin sections especially in cored sections. Implementing the lowest level of vacuum would also reduce RE losses during casting. The tools to predict RE loss rate of known casting conditions and refractory mold systems have been proposed, and are intended to advance our understanding of single crystal casting of CMSX-4 with RE dopants. We have demonstrated that it is possible to add a specific quantity of RE dopant to the alloy bar stock and reliably predict the RE concentration retained in the finished product, relative to casting parameters and component section thicknesses.

\section{Acknowledgements}

The authors would like to acknowledge the EPSRC (grants EP/H022309/1, EP/H500375/1), Rolls-Royce plc. for funding and for the provision of materials and analysis, and Prof. Mark Blamire for provision of facilities. Requests for access to the underlying research data should be directed to the corresponding author and will be considered against commercial interests and data protection. Thanks to Dr Alan Brown for conducting the DSIMS analysis at Lucidon, Stoke on Trent, UK.

\section{References}

1. Y. Ikeda, K. Nil, and K. Yoshihara, "High Temperature Oxidation and Surface Segregation of Sulfur," Trans. Japanese Inst. Met. - Suppl., vol. 3 (1983), 207-214.

2. P. Zhou, J. Yu, X. Sun, H. Guan, and Z. Hu, "Role of $Y$ in the Microstructure and Mechanical Properties of a B-Modified Nickel-Based Superalloy,” Scr. Mater., 57 (2007), 643-646.
3. S. Leyland, "Casting of Single Crystal Nickel Superalloys with Reactive Elements," PhD Thesis,Cambridge University, 2014.

4. J. G. Smeggil, "Some Comments on the Role of Yttrium in Protective Oxide Scale Adherence," Mater. Sci. Eng. A, 7 (1987), 261-265.

5. B.A. Pint, "Progress in Understanding the Reactive Element Effect Since the Whittle and Stringer Literature Review," in Proc. John Stringer Symposium on High Temperature Corrosion, P. F. Tortorelli, I. G. Wright, and P. Y. Hou (eds.), ASM International, Materials Park, OH, (2003), 9-19.

6. K. Harris, "US 2012/0034127 A1 Low Sulfur Nickel Based Single Crystal Superalloy With PPM Additions of La and Y,"

7. P. R. Aimone and R. L. McCormick, "The Effects of Yttrium and Sulfur on the Oxidation Resistance of an Advanced Single Crystal Nickel Based Superalloy," Superalloys 1992,eds. S.D. Antolovich et. al., (Warrendale, PA: The Minerals, Metals and Materials Society, 1992) 817-823.

8. D. A. Ford, K. P. L. Fullagar, H. K. Bhangu, M. C. Thomas, P. Burkholder, P. S. Korinko, K. Harris, and J. B. Wahl, "Improved Performance Rhenium Containing Single Crystal Alloy Turbine Blades Utilising PPM Levels of the Highly Reactive Elements Lanthanum and Yttrium," J. Eng. Gas Turbines Power, 121(1) (1999), 138.

9. C. Mennicke, D. R. Clarke, and J. S. Smith, "The Role of Secondary Oxide Inclusions (PEGS) on the Spallation Resistance of Oxide Films," Acta Mater., vol. 48, (2000), 2941-2949.

10. K. Harris and J. Wahl, "Improved Single Crystal Superalloys.," Superalloys 2004, (Warrendale, PA: The Minerals, Metals and Materials Society, 2004) 45-52.

11. P. Zhou, J. Yu, X. Sun, H. Guan, X. He, and Z. Hu, "Influence of Y on Stress Rupture Property of a Ni-Based Superalloy," Mater. Sci. Eng. A, 551 (2012), 236-240.

12. T. A. Ramanarayanan, M. Raghavan, and R. Petkovic-Luton, "Metallic Yttrium Additions to High Temperature Alloys : Influence on $\mathrm{Al}_{2} \mathrm{O}_{3}$ Scale Properties," Oxid. Met., 22 (1984), 83100.

13. J. Pravratska, "Disorientation Angles and Compatible Walls for Phase Transition Hexagonal to Monoclinic Phase," Phase Transitions, 83 (5)(2010), 388-342.

14. P. Hou, "The Reactive Element Effect Past Present and Future,” Mater. Sci. Forum, 696 (2011), 39-44.

15. J. K. Tien and F. Pettit, "Mechanism of Oxide Adherence on Fe-25Cr-4AI ( Y or Sc ) Alloys," Metall. Trans., 3 (1972), 15871599. 